\title{
DIMENSIÓN ECONÓMICO-POLÍTICA DE LA ESTRUCTURA IDEOLÓGICA EN EL NUEVO ESTADO ROMANO REPUBLICANO ANTERIOR A LA GUERRA DE ANÍBAL
}

\section{THE ECONOMICAL-POLITICAL DIMENSION OF THE IDEOLOGICAL STRUCTURE IN THE NEW ROMAN REPUBLICAN STATE PRIOR TO HANNIBAL'S WAR}

\author{
por \\ JuAN CARLos Domínguez PÉREZ
}

RESUMEN

\begin{abstract}
Frente a la imagen del siglo III AC que se ha sostenido hasta la actualidad basada en las fuentes históricas y literarias de los siglos II y I AC y en muchas tergiversaciones historiográficas, los nuevos hallazgos arqueológicos nos permiten una relectura crítica de éstas y de otras fuentes antes despreciadas para la reconstrucción del modelo social de la época. No obstante, ante la evidencia de que nos enfrentamos a dos modelos sociales incompatibles, parece necesario buscar nuevos instrumentos que nos permitan avanzar en este análisis. En este artículo proponemos un estudio de la estructura ideológica de la época, pero a la luz de los avances que la arqueología nos ha permitido sobre la Economía Política y, en general, sobre los grandes cambios que se producen en esos años en la República Romana.
\end{abstract}

In contrast to the image of the third century BC which has rested on historical and literary sources
from the 2 nd and $1^{\text {st }}$ centuries and many historiographical distortions, the new archaeological
discoveries let us a critic revision of these and other sources which had been previously rejected
for the rebuilding of the social pattern at that time. However, as we are facing two incompatible
social patterns, it seems necessary to look for new instruments to go forward in this analysis.
In this work we have prepared a study of the ideological structure, but according to the advances
the archaeology has allowed us about the Political Economy and, in general, about the great
changes that take place in the Roman Republic in those years.

Palabras claves Historicismo. Modelo social. Tensión religiosa. Prodigio. Desviaciones rituales. Superstición. Ánforas greco-itálicas.

Key words Historicism. Social pattern. Religious stress. Prodigy. Ritual deviations. Superstition. Greco-italic anphoras. 


\section{INTRODUCCIÓN}

Aunque no son muchos los estudios al respecto, en los últimos años se han publicado distintos intentos por reconsiderar la Historia de Roma a lo largo del siglo III AC en una apuesta singular por actualizar esta realidad histórica a los nuevos hallazgos arqueológicos que se han producido. Hasta este momento, la investigación, heredera de un debate historiográfico de marcado carácter historicista y decimonónico, se reducía por lo común a la historia política, materializándose en el problema del imperialismo y/o la conquista y en sus posibles consecuencias institucionales para la República. No obstante, la superación progresiva de esta dinámica monolítica y unidimensional, gracias a los esfuerzos interdisciplinares y al creciente peso específico de los hallazgos relativos, ha transportado el debate hacia nuevas posiciones teóricas cuya validación definitiva puede colocar el hasta ahora asumido modelo social del siglo III -y en particular el del período pre-anibálico- en la antesala de una profunda reformulación.

¿Qué supone el siglo III en la República Romana? Hasta hace muy poco únicamente el espacio cronológico en el que se desarrollan las dos primeras Guerras Púnicas, la lucha por el control del Mediterráneo Central y Occidental,... ¿Aníbal y el Africano? Sin duda, no es ésta la realidad de un siglo que no coincide con el modelo aceptado ni siquiera en el volumen de fuentes reconocidas. Lejos de la imagen que proporciona la ausencia de testimonios históricos contemporáneos (por la pérdida de Fabio Píctor y de los hiistoriadores filo-púnicos, así como de los primeros eslabones de otras líneas historiográficas paralelas), el período que abarca desde la Lex Ogulnia hasta el inicio de la Segunda Guerra Púnica cuenta ya hoy con evidentes datos materiales que nos permiten mantener una posición razonablemente crítica incluso para los años correspondientes a los libros perdidos de Livio.

La mejor manera de evitar esta doble concepción es plantear qué era Roma en el año 300 y en qué se diferencia de la nueva realidad del 218 . Esto nos obliga sin duda a relacionar los hechos con la conocida historia política, pero ello no debe condicionar un análisis que intencionadamente acerca su mirada a otros hechos. Así podremos evitar la excesiva atención prestada a la Segunda Guerra Púnica (cuyo valor traumático, por otro lado, es innegable) por el excesivo sentido decisorio concedido a Polibio, cuya narración histórica adolece de unas orientaciones singulares, algunas de las cuales no se toleraría hoy ni como defecto de principiante a un historiador de nuestra era ${ }^{1}$.

En líneas generales consideramos que la historia de la Roma Republicana "adulta" no sólo no comienza con la Segunda Guerra Púnica, sino que las profundas transformaciones que subyacen en su nueva dimensión de potencia mundial se producen a lo largo de este período pre-anibálico y que esta maduración social, económica, institucional y política sufre importantes crisis con los dos conflictos bélicos romano-púnicos. Es decir, que la supremacía de Roma visible ya en el siglo II se fragua en procesos socio-económicos antebélicos por lo menos en igual medida que en los procesos políticos con los cartagineses. Esto evidentemente no quiere decir que existan dos líneas paralelas de desarrollo histórico, aunque sí una evidente priorización de objetivos socio-económicos condicionada por la propia urgencia de los acontecimientos políticos y militares. Basta echar un vistazo a una cronología comparada de todos estos acontecimientos por separado para comprobar hasta qué punto determinados desarrollos cualitativos seculares sufren abandonos periódicos coincidiendo con una dedicación plena a conflictos en los que se ventila la continuidad del modelo republicano, bien frente a un enemigo exterior, bien frente a amenazas de "revolución democrática".

1. El problema principal es la mal considerada "actualidad" de su modelo historiográfico que, como es lógico, posee unas claves culturales esenciales propias de otros modelos anteriores que le sirven de referencia (básicamente Tucídides y las aportaciones que él siempre rechaza de los historiadores helenísticos, incluido el denostado Timeo de Tauromenio). Una aproximación al estudio del tema -centrado en el debate del imperialismo-puede encontrarse en mi Memoria de Licenciatura (inédita). (Domínguez Pérez 1995: 36-47). 
En este punto del debate es donde resulta imprescindible encontrar nuevos elementos de juicio que permitan un análisis de las transformaciones socio-económicas del siglo III. Se trata de definir una serie de "termómetros" que nos permitan medir el grado de actividad social, los niveles de ruptura entre grupos sociales, de cohesión entre los grupos oligárquicos y de organización entre los grupos populares, de alineamiento interclasista en torno a una familia o de fractura de la estructura clientelar en favor de estas diferencias sociales. También se trata de establecer hasta qué punto estas nuevas transformaciones sociales y económicas, pero también políticas (la nueva oligarquía patricio-plebeya, la irrupción del comercio y la economía monetaria, los beneficios de la conquista, la explosión demográfica, la acumulación material,...) están produciendo la elaboración de un nuevo código de conducta del ciudadano republicano, lejos ya de la austeridad y de la humildad, la solidaridad y el sentido ético con que las fuentes pretenden caracterizar los primeros tiempos de la República.

Por otro lado, no deberíamos perder de vista los principios en que el Estado romano fundamenta su modelo social: la importancia crucial del reparto de la propiedad y la propia división social del trabajo según las condiciones impuestas por el régimen de propiedad y la definición consecuente de la posición social individual. Sobre estas condiciones de la Economía Política se instituye el modo de producción y distribución de los tres elementos básicos del sistema: (por este orden) la fuerza del trabajo, las materias primas y los productos de uso y consumo. Tratar de esbozar las transformaciones de la Roma del siglo III AC es ni más ni menos que proceder al estudio de cómo se elabora progresivamente el complejo estructural de esta formación económicosocial y, decididamente, qué peso tienen en esta elaboración las distintas estructuras regionales que conforman la estructura global. Tradicionalmente el peso académico y el rechazo a la interdisciplinaridad han impedido la confluencia de estos estudios llamados a hacer converger en un mismo marco conceptual aparatos documentales procedentes de ámbitos dispares. Hoy ya no sólo es posible, sino sobre todo deseable enfrentar con armas distintas disciplinas que en el fondo tratan de lo mismo por vías alternativas. Esa es nuestra intención al buscar en el singular aumento de la tensión religiosa que se produce en este siglo III AC elementos que pueden enriquecer a los que ya tenemos procedentes del campo de la arqueología subacuática o de campo (ánforas greco-itálicas arcaicas, productos del Taller de Pequeñas Estampillas,...). En suma, de lo que se trata es de intentar precisar el peso que en la definición definitiva de la formación económico-social que estudiamos tiene la superestructura ideológica (religiosa, jurídico-política, irracional), amparada en coartadas institucionales que garantizan la reproducción incuestionable de las relaciones de producción a través de la clase dirigente que gestiona en su provecho el Estado.

\section{LA TENSIÓN RELIGIOSA REPRODUCE LA NO-CORRESPONDENCIA ENTRE LAS NUEVAS Y LAS VIEJAS RELACIONES DE PRODUCCIÓN}

Para ello una referencia importante puede ser el análisis de los distintos acontecimientos religiosos en el período de estudio. No es éste el lugar apropiado para dar una valoración de la importancia del fenómeno religioso de la época en Roma (Scheid 1991:99-118)2. Aún así, no resulta innecesario afirmar que su particular trascendencia en el modelo social romano procede, en primer lugar, de su alto grado de vinculación al poder político y, por tanto, de su crucial representatividad de la orientación del modelo de estado que pretende la clase dirigente; pero también es importante por su nivel de referencia de actitudes oficiales, públicas y privadas, o, lo que es lo mismo, por su función moralizadora, por su potencialidad creadora de la ética social de la época. En este sentido, en numerosas ocasiones, los distintos colegios sacerdotales se convierten en instituciones

2. Y, sobre todo, algunos textos significativos como Pol. VI 56, 7-12 (infra); Liv. V 14, 2; VI 1, 10 (para principios del siglo IV AC); VIII 23, 13-16 (327/6 AC). 
fundamentales para el control del orden público, así como en instrumentos de la oligarquía y las familias para la gestión interesada de lo público, que frecuentemente se patrimonializa. Por otro lado, también es fuente de reivindicaciones sociales plebeyas y su concesión no es más que un nuevo episodio de renuncia calibrada del patriciado y una apertura mínima a la participación de los ricos plebeyos de los beneficios políticos, sociales y económicos del nuevo Estado romano. Polibio es quien puede valorar en su justa medida esta importancia política de la religión en la sociedad romana. Como griego y como historiador preocupado de la historia político-militar se admira de la presencia de lo religioso en todos los asuntos públicos y privados, en una época marcada por el descrédito de las distintas confesiones en el Mediterráneo ${ }^{3}$. Su certero análisis de la función social del miedo a lo desconocido en el mundo antiguo contribuye a centrar nuestro tema.

Lejos de ser una manifestación individual y de fe, a lo largo del siglo III, en un proceso paralelo y asociado a la elaboración de la política imperialista y del resto de las grandes transformaciones económicas, el volumen de actividad religiosa se dispara bajo la celosa gestión del Estado. Asistimos en este período a la proliferación de nuevos cultos y celebraciones religiosas, a la recopilación y difusión de gran cantidad de prodigios, mientras que el poder público se esfuerza con rigor en el control de las desviaciones rituales; se recurre en ocasiones de singulares tragedias o de alarma social a la consulta de oráculos extranjeros. La maquinaria estatal romana, con la misma finalidad que empieza a naturalizar ciertos colectivos foráneos de interés, comprende que es igualmente necesario asimilar a sus dioses y sus ritos en un desarrollo histórico que marca las directrices del nuevo modelo de estado, tendente a una federación de intereses itálicos bajo la hegemonía y la orientación romanas. Se procede también a la construcción de nuevos templos y santuarios con los beneficios materiales que reporta la conquista. A la vez, es evidente que la clase dirigente está desarrollando un singular esfuerzo por dar cobertura moral a su gestión, cuya esencia progresivamente se aleja del mos maiorum republicano uniendo el respaldo de los dioses a su política imperialista. Finalmente se procede a la redefinición o nueva creación de celebraciones religiosas como los Festivales Latinos, los Ludi Seculares, Apollinares y Plebeii, las Cerealia, Epulum Iovis, en una sucesión continua que llega a finales del siglo III.

Esta incesante actividad religiosa pública tiene su referencia en otros procesos igualmente complejos de reestructuración de los fundamentos del Estado. Como se ha dicho, a lo largo del siglo y sobre todo en los años que anteceden a la Guerra de Aníbal, se sientan las bases definitivas y los nuevos objetivos de la república imperial: la asimilación de la economía monetaria y del comercio como fuente de riqueza, el control de los principales mercados, la política de conquista, la colonización, la conformación del nuevo Estado patricio-plebeyo y del régimen oligárquico aunque con simbología aristocrática, la progresiva presencia internacional a través de tratados, alianzas y arbitrajes, y, por último, la provincialización y la tributación de los nuevos territorios. Cuanto sucede en un campo como es la religión oficial tiene, por tanto, una ligazón tan estrecha con el Estado como pudiera tenerla la deducción de una colonia, la firma de un tratado o una nueva legislación. Tanto es así que son los mismos personajes los que gestionan estos campos, sin existir más barrera que la duración del nombramiento y las funciones propias reconocidas a cada magistratura. Las autoridades políticas, militares y religiosas incluso llegan a sustituirse en ocasiones excepcionales ${ }^{4}$ reconociéndose entre sí mismos como legítimos depositarios de los distintos atributos del poder (imperium,

3. Pol. VI 56, 7-12: "Y me parece también que ha sostenido a Roma una cosa que entre los demás pueblos ha sido objeto de mofa: me refiero a la religión. Entre los romanos este elemento está presente hasta tal punto y con tanto dramatismo, en la vida privada y en los asuntos públicos de la ciudad, que es ya imposible ir más allá. Esto extrañará mucho, pero yo creo que lo han hecho pensando en las masas. Si fuera posible constituir una ciudad habitada sólo por personas inteligentes, ello no sería necesario. Pero la masa es versátil y llena de pasiones injustas, de rabia irracional y de coraje violento; la única solución posible es contenerla con el miedo de cosas desconocidas y con ficciones de este tipo. Por eso, creo yo, los antiguos no inculcaron a las masas por casualidad o por azar las imaginaciones de dioses y las narraciones de las cosas del Hades; los de ahora cometen una temeridad irracional cuando pretenden suprimir estos elementos".

4. En plena Tercera (Segunda) Guerra Samnita, concretamente en 295 AC, el Pontífice asume las funciones de pretor por delegación del cónsul P. Decio Mus. Liv. X 29, 3-4. 
potestas, auctoritas, arbitrium,...), a pesar de la espesa delimitación y control de sus acciones, como si se tratara al fin y al cabo de las distintas caras de una misma moneda o, más exactamente, de proyecciones distintas de una misma realidad focal ${ }^{5}$.

El proceso no puede tener una fecha de inicio más manualística: la promulgación en $300 \mathrm{AC}$ de la Lex Ogulnia por la que se daría definitivamente los colegia de Pontífices y Augures a los plebeyos. Suponía una nueva concesión por parte de los patricios, en la línea de redefinición del Estado, de igual trascendencia que las futuras Leges Hortensiae ( $287 \mathrm{AC}$ ), que supondrían la equiparación final de los dos grupos sociales y la superación teórica del conflicto. Resulta evidente que la "democratización" de los colegios sacerdotales era una claudicación de la aristocracia en favor de la nueva (y rica) nobleza plebeya, que ahora también podrá gestionar el favor de los dioses y repartir el patrimonio público en asignaciones privadas con la misma legitimidad que secularmente habían disfrutado las grandes familias patricias.

Pero, precisamente por ello, el Estado desarrolla su propio sistema "inmunológico", a la altura de los nuevos riesgos. La lista de actuaciones contra todas aquellas desviaciones, tanto cívicas o morales como en el cumplimiento del ritual, es incuestionable. Ya en 296/5 curiosamente los mismos Ogulnios que habían presentado la ley de acceso de la plebe al sacerdocio presentan como ediles curules una demanda contra los usureros que se salda con una multa que se emplea en equipamiento sacro y obras viarias (Liv. X 23, 11-12). El mismo año los ediles de la plebe Aelio Paecio y Fulvio Corvo sacan adelante sus demandas por extralimitación contra los arrendatarios de los pastos públicos y con el dinero de las multas celebran juegos y ofrecen cálices de oro a Ceres (Liv. X 23,13). Con todo, se siguen manteniendo poderosos intentos de mantener las diferencias sociales que la ley poco a poco estaba borrando. En 295 se crea el culto a la Pureza Plebeya como respuesta de éstas al rechazo de las matronas patricias a aceptarlas en su profesión de fe (Liv. X23,1-10). Antes de terminar el año se producen en Roma diversos prodigios (lluvia de tierra, rayos,...) que sumados a las epidemias llevan a consultar los Libros Sibilinos ${ }^{6}$ y se sanciona a las matronas adúlteras, con cuyas multas se inicia la construcción del Templo de Venus (Liv. X 31, 9).

El espíritu general lo muestran hechos como el falseamiento de los auspicia ante el afán por emprender una batalla con aspecto de rentable para el general al mando (Liv. X 40,4-12) o la vinculación de los dioses con la guerra justa (manifestación de la ya explicada asociación de la religión al poder) (Liv. X 39, 14-17), pero también interpolaciones del mismo Livio como cuando se refiere a un joven de la época cuya virtud se debía a un hecho muy significativo: había nacido-literalmente- "antes de que se enseñara el menosprecio de los dioses" (Liv. X 40, 10). En el mismo año, 293, el cónsul Papirio, tras un desfile triunfal cargado de ostentación, decide dedicar un Templo a Quirino con parte del dinero conseguido como botín (Liv. X $46,2-8$ ), al igual que el año anterior había hecho su antecesor en el cargo, Postumio, con dinero de nuevas multas, dedicando el Templo a Victoria (Liv. X 33, 9).

Estas dos serán las fuentes principales en la construcción de todo tipo de obras públicas por parte del Estado romano, tanto religiosas como civiles, junto a otras posibilidades que se van abriendo poco a poco ante los magistrados romanos ${ }^{7}$, sin contar con los impuestos ordinarios. Las instituciones republicanas rentabilizan, como es evidente, su potencial, pero de camino aprovechan la situación para ejercer con autoridad

5. El hecho llega a extremos más llamativos de dependencia a partir de la Segunda Guerra Púnica, cuando se aprecia que los distintos colegios sacerdotales sirven para iniciar en las funciones de magistrados a miembros de la nobleza cuya inexperiencia política desaconsejaba su elección para puestos de extrema responsabilidad en el Estado (Szemler 1972: 193).

6. Liv. X 31, 8. El año anterior también se habían producidos distintos prodigios: Liv. X 23, 1; Dio VIII (Zon. VIII 1, 3). Una relación de los prodigios de la época en Macbain 1982, 86-90.

7. En concreto la venta de prisioneros de guerra, cuyo volumen (en torno a los 65.000) sólo durante la Tercera Guerra Samnita es tan impresionante que los especialistas dudan entre si su fin era la venta o el trabajo en la propia Roma, con la conciencia de que ambas posibilidades obligan a aceptar un modelo social muy distinto al propuesto para principios del siglo III. Otras formas de financiación para el Estado son la venta individualizada a los prisioneros de su libertad (Liv. X 46, 10) o la venta de parte del botín material conseguido (Liv. IX 18, 6; X 17, 6; X 37, 5). 
el gobierno y evitar desarrollos constitucionales democráticos. La asimilación de los nobles plebeyos es una medida de reforma del Estado en contra de la revolución ${ }^{8}$, pero las reglas de juego, el equilibrio de la República, deben seguir basándose en las mismas estructuras oligárquicas. Es decir, se aumenta el número de invitados a la mesa, pero se mantienen el menú, la disposición de los comensales y el protocolo, de momento.

En 293 reaparecen las epidemias y se vuelven a consultar los Libros Sibilinos que esta vez optan por una solución exterior: traer de Epidauro a Roma la serpiente de Asclepio (Liv. X 47, 6-7; Per. XI). Para ese fin es nombrado jefe de la expedición un personaje que ya a estas alturas nos resultará conocido: Quinto Ogulnio, cuyo encargo acaba con la construcción del Santuario de Esculapio (Asclepio) en la Isla Tiberina en 291 (Val. Max. I 8, 2. Cf. Liv. X 47, 6-7; Per. XI).

El período analizado (del 300 al 291) supone un incuestionable aumento de la tensión religiosa, que coincide básicamente en lo político con la Tercera Guerra Samnita (298-290) y en lo social con un nuevo período de reformas definitivas sólo comparables a las del 287 y que con seguridad van indisolublemente unidas. En la práctica resulta una aceleración de los desarrollos cualitativos iniciados años atrás ante el no siempre acertado intento de la nobleza por ponerle freno. En estos escasos diez años, por otra parte, se dispara el número de construcciones religiosas, que prácticamente se salda con una media de un nuevo templo cada año (Liv. X), una realidad material que puede razonablemente plasmar el interés político en asimilar los cultos foráneos y en desviar la atención del pueblo, pero que conducirían inexorablemente a la fragmentación del sentido religioso romano y, con ello, a la pérdida de efectividad social de los rituales asimilados. En un proceso de desgobierno progresivo, estos hechos llevarían a la larga a la crisis de la religión oficial ya en la Segunda Guerra Púnica y a la proliferación de ritos mistéricos y de salvación individual contra los que el mismo Estado tendría que actuar mediante su represión.

En estos momentos -290 AC- Roma alcanza ya una cifra de población en torno a los 270.000 (así se deduce del censo realizado al año siguiente que lo concreta en 272.000: Liv. Per. XI), hecho que supone que prácticamente ha duplicado el número de ciudadanos en el último siglo. Esto la obliga a mantener un alto nivel de asistencia pública para alimentar a las masas -que no siempre consigue-y para evitar perder el control político de la situación. La continua movilización-lo que garantiza la maleabilidad del colectivo ciudadano más activo a través de la disciplina militar-mantiene grandes contingentes populares lejos de la ciudad y cuando la guerra deja de ser estacional y no se regresa a casa para el invierno o las labores agrícolas (Liv. V 2), el Estado se tiene que imponer una nueva necesidad: pagar a los soldados para su mantenimiento (Liv. IV 59, 11) y emplear esclavos en los campos, además de importar grandes cantidades de trigo ${ }^{9}$. Otra necesidad acuciante, la del agua, se cumplirá años después, en 272, momento en el que se finalizan las obras del Acueducto sobre el Viejo Anio iniciadas por el censor Curio Dentado de su parte personal del botín arrancado a Pirro (Front. Aq. I 6. Cf. sobre el botín Val. Max. IV 3, 5 y Plin. NH XVI 185).

La victoria definitiva sobre los samnitas produce considerables efectos de relajación en la tensión religiosa acumulada. Tanto es así que hasta el 278 no están atestiguados nuevos prodigios. Pero ese año, después de las derrotas romanas de Heraclea y Ausculum contra Pirro ( 280 y 279 ), vuelven a aparecer viejos fantasmas: "la estatua de Júpiter fue derribada por un rayo en el Capitolio, su cabeza fue hallada por mediación de los arúspices" (Liv. Per. XIV). Sextilia, una joven Vestal, fue condenada por incesto y enterrada viva. Desde la aprobación de las Leyes Hortensias, tras la última secesión plebeya, ni siquiera se habían producido nuevas edificaciones templarias. Pero Pirro, como después hiciera Aníbal, llega a esperar en territorio latino la rendición de Roma, aunque ésta no se produce. El Senado y el pueblo son conscientes de que está en

8. Curiosamente siempre está en el ánimo de la clase política romana, de manera velada o más explícita, el ejemplo ateniense. Dracón y Solón, por ejemplo, tienen en la Historia de la Roma medio-republicana poderosos reflejos reformadores.

9. Sobre la carestía en Roma y las actuaciones emprendidas por el Estado: Liv. IV 12, 8-10; 25, 4 (ambas para el siglo V AC); V 13, 1 (para el IV AC); y, finalmente, X 11, 9. Además, se hacen frecuentes desde finales del IV AC en los tratados de paz las cláusulas que obligaban al aprovisionamiento del ejército romano como una de las condiciones exigidas por Roma a los pueblos vencidos: Liv. IX 41, 5; 43, 6; 43, 21; 45, 4. Más tarde, también se pedirá la paga de los soldados: Liv. X 46, 12. 
peligro la propia supervivencia de la República. Ese mismo año se reanuda la actividad constructora de nuevos centros de dedicación religiosa con el Templo de Summanus en el Circo Máximo. De aquí al 264 se levantarán también los de Consus (272), Tellus (268), Pales (267) y Vertumnus (264).

Vuelve a acelerarse el pulso irracional y supersticioso del pueblo y los colegios sacerdotales intentan de nuevo reconducir el proceso a través de la interpretación ventajosa de estos hechos. En este período que abarca hasta la Primera Guerra Púnica se suceden los prodigios (y las formas de expiación oficiales), acompañados de nuevos episodios epidémicos que resultan inseparables en la mentalidad popular (Macbain 1982: 86). En 266 otra Vestal, Caparronia, decide ahorcarse para no hacer frente a la acusación de incesto y a la más que posible pena de ser sepultada viva. Se apunta, significativamente, que "su corruptor y los siervos que ocultaron el hecho fueron también llevados al suplicio" (Oros. IV 5, 9).

En general, desde el $290 \mathrm{ni}$ el riesgo para la República ha sido permanente (salvo el momento crítico de Pirro en 279/8 AC) ni existe una crisis general que justifique el temor; pero el Estado, después de la primera década del siglo, ha sabido de la utilidad de éste y de la conveniencia de manejar con firmeza todos los argumentos del poder. Lo que se pretende ahora es que el pueblo abandone el camino de las reivindicaciones sociales -que ya se prolongaban por espacio de un siglo-y para ello la solución pasa por dos medidas tan elementales como son alejar a las masas de sus preocupaciones materiales con el temor a los dioses y al futuro y ciertas satisfacciones en la línea de un evergetismo primitivo y alejar a los ciudadanos-soldados del centro político mediante su destino en objetivos militares cada vez más alejados y duraderos. Es evidente que es en este desarrollo tanto repercute en la tensión final el miedo a la muerte en casos de victoria como de derrota. La angustia es la misma independientemente del resultado final y, en ese caso, la reconducción como acción de gracias también implicaba actividades frenéticas, ofrecimientos y sacrificios, incluidos -más tarde- los humanos ${ }^{10}$. Uno de los mejores textos que nos han llegado para explicar estos momentos nos lo ha proporcionado Polibio (III 112,6-9), quien refleja la crisis religiosa del 216 sin olvidar que la referencia es aplicable a otros momentos similares de la historia reciente de Roma. La cita no tiene desperdicio:

"Cuando en Roma se enteraron de que los dos ejércitos estaban acampados frente a frente y que cada día se producían refriegas de avanzadillas, la ciudad estaba animada y temerosa. El pueblo temía por el futuro, puesto que se habían sufrido tantas derrotas; suponían y se imaginaban ya en sus pensamientos lo que les iba a ocurrir si ahora les sobrevenía un descalabro total. Todos los oráculos que tenían entonces corriendo de boca en boca, todo templo y toda casa rebosaba de signos y de prodigios; de ahíque plegarias y sacrificios, súplicas e imploraciones a los dioses agitaran la ciudad. En las circunstancias difíciles los romanos tienden a propiciarse dioses y hombres, y no juzgan nada indecoroso o innoble si se hace en tales tiempos".

En el 264, a pesar de estar inmersos en un conflicto bélico de dimensiones impresionantes, los romanos aún no son conscientes de ello. Han decidido participar en la lucha por Sicilia menospreciando el riesgo para la República y convencidos de su pronta y favorable resolución acompañada de importantes beneficios públicos y privados. Los éxitos iniciales (Agrigento, 262; Mylae, 260; Tyndaris, 257; y Ecnomon, 256) no hacen previsible el curso posterior de los acontecimientos; además, se ha conseguido que Hierón de Siracusa garantice el aprovisionamiento de las tropas de Sicilia y se ha iniciado la ocupación de Córcega. En este tiempo únicamente rompen la nueva calma de la actividad religiosa ciertos hechos aislados -aunque simbólicos-: la dedicación de un Templo a las Tempestades (259), a la Esperanza (258) y a la Fe (254). Por otra parte, también en 254 alcanza el Máximo Pontificado el primer plebeyo, Tiberio Coruncanio (Liv. Per. XVIII)

10. El primer sacrificio humano se produce en 225 y se repetirán en 216,209 y 207, durante la crisis de la Segunda Guerra Púnica. Sobre la introducción de sacrificios expiatorios extranjeros desde el V AC: Liv. IV 30, 9-11. Otras medidas para restaurar la pax deorum, todas en Livio: lectisternios (V 13, 4-8; VII 2, 2; 27, 1), recuperación de los cultos patrios (V 15; 16, 8-11) e introducción del teatro (VII 23). 
(ha pasado casi medio siglo desde que se suprimieron los obstáculos legales para ello); mientras, el Estado maniobra libremente en la idea de reforma consensuada con la nobleza plebeya.

Pero "el naufragio de las flotas -al menos dos: en 255 en Camerina y en 253, de regreso de África en Cabo Palinuro-deslució los éxitos obtenidos a continuación por todos los generales romanos por tierra y mar" (Ibídem). El anterior desembarco de Régulo en África en un intento por decidir la guerra, acaba por darle un giro inesperado al que se suman nuevos y contundentes reveses: el asedio frustrado de Lilibeo (250) y las derrotas claras de Drépano y Camerina (249). Ese mismo año curiosamente reaparecen los prodigios y los juicios populares y se instituyen nuevas celebraciones religiosas. $\mathrm{Al}$ año siguiente de su consulado Claudio Pulcher es procesado por perduellio y multado con 120.000 ases -aunque absuelto-por arrojar por la borda de su barco las aves sagradas ante la poca conveniencia de los auspicios que éstas le otorgaban (Val. Max. I 4, 3; VIII 1 a, 4; Liv. Per. XIX; XXII 42, 8; Pol. I 52, 3). Su colega Junio Pullo, acusado igualmente de ignorar el dictado de los auspicios, temeroso de no contar con el respaldo político de aquél, opta por suicidarse para no hacer frente al proceso (Val. Max. I4,4). Ese mismo año-249-se celebran por primera vez los Ludi Saeculares y el dictador Claudio Glicia, que había sido elegido por el cónsul Claudio, es obligado a abdicar, pero se niega a entregar los símbolos de la magistratura (Liv. Per. XIX). Poco después, en 246, se multa a la hermana del mismo Claudio procesado por pronunciarse-mientras sufría al salir de unos juegos los apretones de la multitud-a favor de que su hermano disminuyera nuevamente la población de Roma con otros tantos desastres navales como los que había protagonizado (Liv. Per. XIX; Val. Max. VIII 1 b, 4). Con el dinero de su multa (25.000 ases) se procedió a la construcción del Templo de Libertas.

Como se ve, el Estado ahora apunta "a la cabeza" de cualquier intento de desviación, pero quién lo gestiona en este momento. Los principales procesos públicos referidos son emprendidos por tribunos o ediles de la plebe que los convierten en procesos políticos populares contra los elementos más reaccionarios de la nobleza patricia. A la vez, estas actuaciones, que gozan del respaldo del pueblo sabiamente manejado, son el trampolín de estos líderes para empresas políticas más altas. Cayo Fundanio Fúndulo, por ejemplo, uno de los tribunos que condujeron el proceso contra Claudio, que hasta ese momento no había desempeñado ninguna magistratura importante, alcanza el consulado-la más alta magistratura-apenas cinco años después (Broughton 1968: 215 y 217), aunque a medio camino se había encargado también -"de paso"-, ahora como edil, de procesar a la hermana de aquél por el asunto arriba mencionado. En este nuevo proceso lo asiste Tiberio Sempronio Graco, que accedería de igual forma al consulado pocos años después, concretamente en 238 (Ibídem: 216 y 221).

La rentabilidad política de las causas que ahora pasan a defender los populares está clara por tanto. Ondeando la bandera de la tradición, del respeto al mos maiorum y como estrictos cumplidores de la ley romana, aceptada por los hombres y sancionada por los dioses, todas las actuaciones públicas son examinadas con lupa, todos los procedimientos rituales, los nombramientos oficiales, el sobrio cumplimiento de las funciones, la puntualidad y pulcritud en los procesos adivinatorios. En cada error ajeno hay una posibilidad de futuro, en cada denuncia fundada contra patricios una carga de popularidad que diestramente manejada pondrá en las manos el consulado y, tras él, el cargo de senador vitalicio ${ }^{11}$. Aunque esta política en ocasiones se volvió contra los populares ${ }^{12}$, siguió dando otros casos similares cuyos resultados finales no siempre conocemos por las lagunas existentes aún en algunas de las magistraturas de estos años.

El año que finaliza la Primera Guerra Púnica (241) recoge la condena popular de los triumviri nocturni (Mulvius, Lollius y Sextilius) por llegar tarde a un incendio en la Vía Sacra (Val. Max. VIII 1 b, 5 -aunque

11. Una visión ciertamente timorata de este proceso puede verse en el artículo de Develin 1978: 3-19. Y, más al hilo de los acontecimientos políticos, pero sin relacionarlos con los económicos en Buono-Core Varas 1988: 7-19.

12. En 226, por ejemplo, se condenó al edil de la plebe C. Scantinius por "intentar corromper" al hijo de Claudio Marcelo, que ese mismo año era, además de edil curul, augur y que había sido cónsul en 222, 215, 214, 210 y 208 y pretor en 224 (?) y 216. Val. Max. VI 1, 7; Plut. Marc. II 2-4. Broughton 1968: 230. 
sitúa este hecho erróneamente en 168 AC-), pero, sobre todo, la construcción por parte de los ediles de la plebe del Templo de Flora cerca del Circo Máximo y del Clivus Publicius, así como la institución de la Floralia (Vell. I 14, 8; Plin NH XVIII 286). Uno de estos ediles, M. Publicius Malleolus, alcanzaría el consulado en 232 . Ese mismo año aparece en escena también como tribuno de la plebe C. Flaminio, que pasaría a la historia de la República como instigador de medidas revolucionarias por sacar adelante contra la oposición de todo el Senado la distribución del ager gallicus y picenus (que la aristocracia terrateniente pretendía apropiarse distraídamente y hacerla suya de manera consuetudinaria) en asignaciones individuales. Gracias a ello fue pretor en 227 y cónsul en 223 y 217 (Pol. II 21, 7-8; Liv. XXI 63, 2; Val. Max. V4, 5; Cic. Sen. XI. Broughton 1968: 225). Es evidente a estas alturas que el Estado, para el diseño de su política y la elaboración de sus nuevas bases, siempre está inspirado en la idea del mantenimiento del modelo establecido. El rechazo de cualquier desarrollo constitucional democrático es vigilado muy de cerca y sirve incluso como arma arrojadiza en las luchas políticas internas y su adjetivo como insulto entre los patricios cuando es necesario. Se transige en un elemental reparto de las fuentes de riqueza con los nuevos plebeyos ricos, pero no se admite ninguna discusión sobre el modelo oligárquico.

En este período mal llamado de entreguerras -puesto que el Templo de Jano sólo se cierra en 235 (Varro $L L$ V 165; Liv. I 19,3; Vell. II 38, 3)- se agudiza la lucha interna por el poder y para ello se retoman los argumentos ya antes utilizados. En 231 los censores son obligados a abdicar por irregularidades en su elección y en 223, por errores en el ritual, también son obligados a abdicar los flamines dialis. En 220 se llega incluso a sustituir a los cónsules electos por dos nuevos argumentando nuevamente irregularidades en el proceso (Broughton 1968: 226, 232 y 235). En estos mismos años se reanuda la construcción de edificios de cultos: el Templo de Honos (233), el de Fons (231) y el de Virtus (222). En 221 se instituyen los Ludi Plebeii. Las medidas populistas ya se han convertido en una condición para quienes, aún siendo patricios, no tienen garantías de acceso al poder debido a la dura lucha por él.

Esto hace que ciertas cuestiones "de estilo" características de los aspirantes plebeyos se incorporen al lenguaje político de la mayoría de los candidatos electorales. De fondo, lo que se está ventilando es, una vez más, la gestión del Estado. Pero no sólo el reparto de las distintas parcelas de poder, sino, sobre todo, la delimitación estructural del acceso a las fuentes de riqueza que la potencia romana administra directamente a través de sus instituciones públicas. A lo largo del siglo III y ya antes de la Segunda Guerra Púnica, gracias a la conquista y a la irrupción ventajosa que ésta garantiza en los circuitos comerciales del Mediterráneo Central y Occidental hasta ahora controlados por los griegos italiotas y los púnicos, la República ha modificado sustancialmente sus fundamentos económicos. La continua afluencia de riquezas, fruto del control de las rutas de distribución, de la intensa labor conquistadora y la administración posterior de los poblaciones sometidas, ha acabado por alterar definitivamente el modelo social romano. Difícilmente se puede mantener para esta fecha el carácter autárquico y agrícola del modelo tradicional. Roma ya no vive del trabajo de sus campesinos, sino de la extorsión de los mercados y del pillaje de sus soldados. No estamos hablando ya de una actividad estacional, sino de un proceso encadenado que sólo se interrumpe el año 235. Como demuestra la Lex Claudia contra la actividad comercial de los senadores romanos (del 218) hay ya muchos conceptos en los que la República ha cambiado. Roma ha convertido la guerra en su principal negocio de Estado y, a través de éste, los nobles. Pero a esta tarta también aspiran los novi, cuyas aspiraciones políticas obligaría nuevamente a una apertura que rechaza la nobleza patricio-plebeya. La solución pasa por trasladar esa apertura a las fuentes de riqueza que la guerra garantiza, por permitir el acceso de estos nuevos ricos también a las posibilidades de enriquecimiento que el Estado proporciona en calidad de gestor de los territorios ocupados.

En esta coyuntura y a pesar de la advertencia previa del Senado sobre la protección romana que amparaba a la ciudad ibérica (Pol. III 15, 5), Aníbal toma Sagunto. Hacía tiempo que la rápida recuperación económica cartaginesa, tras la derrota en la Primera Guerra Púnica y las duras condiciones impuestas por el Tratado de Catulo, preocupaba a todas las esferas de poder de Roma. En ese momento vuelve a aparecer la dimensión divina de los asuntos romanos en la tierra. La embajada romana a Cartago portaba órdenes claras de presentar 
la tradicional rerum repetitio (Pol. III 20, 6-10), una fórmula que exigía de la parte contraria la reconsideración de su postura para, en caso contrario, declarar formalmente la guerra. Agotados todos los trámites de oficio y garantizado por medio de ellos el favor de los dioses, los romanos estaban convencidos de que la victoria sería segura porque la guerra era justa. De ahí su especial cuidado en el cumplimiento del ritual. Nuevamente, con ello, la República encontraba en la religión el mejor apoyo para la movilización. Los acontecimientos que siguen repiten conductas sociales que ya hemos tratado llevadas ahora hasta las últimas consecuencias. El ritmo de la actividad religiosa (prodigios, celebraciones, sacrificios, supersticiones,...) hierve en los momentos más críticos y el Estado, actuando como había hecho a lo largo de todo el siglo III, pierde el control de estas manifestaciones. Ello impondrá una traumática corrección de las prácticas y un camino de vuelta al emprendido con el inicio de la conquista. Se persiguen y se reprimen con dureza los ritos foráneos y se incentiva el culto a los dioses “patrios". En este sentido sí se ha cumplido ya una etapa y mientras ahora empieza lo que muchos especialistas consideran el período de imperialismo y de expansión, el Estado, en su más genuina dimensión ideológica del poder, procede a un celoso proceso de regresión dispuesto a no ceder ni un paso en los avances que ya ha conseguido para consolidar su modo de producción. Dicho de otra manera, igual que en un primer momento los nuevos cultos habían supuesto, partiendo de un proceso de adaptación, las bases ideológicas y políticas de la nueva Roma (que desbordaba sus fronteras para reunir bajo su hegemonía un número cada vez mayor de ciudades), la nobleza gobernante recurre ahora al otro recurso político de su lucha contra la revolución: la vuelta a los valores más conservadores de la tradición.

\section{SAGUNTO COMO “CASUS BELLI”TAMBIÉN DEMUESTRA ESTA NO-CORRESPONDENCIA}

El mismo caso de Sagunto puede servirnos de guía para llevar el hilo de esta trama dialéctica. Elegida como casus belli desencadenante de la Segunda Guerra Púnica, esta población del litoral ibero mediterráneo recoge en su significación en gran medida cuanto desde un principio venimos denunciando. En la historiografía analista pro-romana simboliza por sí misma la perfidia de los cartagineses, que cercan y asaltan la ciudad a sabiendas de que estaba bajo la protección de Roma (y de que ésta advierte a Aníbal en repetidas veces de ello), en un intento desleal por romper los tratados, en concreto la cláusula referente a los aliados de la Paz de Catulo del 241 AC (Pol. III 15, 5; Liv. XXI 6, 3-4; Fl. I 22; II 6). En la misma línea, se recoge a los saguntinos como ejemplos de fidelidad al pueblo de Roma y respetuosos con el tratado de amicitia establecido-supuestamente-años atrás (Pol. III 30, 1; 76, 2 y 97, 2; Liv. XXI 60, 3; App. Ib. 7; Oros. IV 14; Nep. Hann. 2). Esta cuestión resulta significativa porque el cumplimiento de los tratados, que recordemos se firmaban poniendo a los dioses como testigos, suponía ni más ni menos que el respaldo de éstos en los acontecimientos futuros y consecuentemente garantizaba si era necesario emprender una guerra que ésta sería justa y, por tanto, se decantaría en su resultado final por la parte ofendida. Esta era la naturaleza del concepto del bellum iustum, manejado por Roma a su antojo durante todo su proceso de expansión. De ahí que Roma dejara caer la ciudad en manos de Aníbal. Un cerco no era bastante. Se necesitaban hechos consumados. Roma tuvo tiempo de mandar fuerzas que defendieran la plaza, pero sólo le valía que los cartagineses forzaran la fides que los saguntinos habían depositado en ellos y que los dioses romanos respaldaran con sus fuerzas y su ira las intenciones bélicas del Senado romano, a sabiendas de que la guerra acabaría con uno de los dos contendientes y de que los sacrificios serían muchos en los próximos años.

Esta es la tradición más oficial, pero tenemos otras fuentes que nos permiten cuestionarla. De la ciudad se dice que había sido fundada por colonos griegos venidos desde el Mar Jonio (Sil. Ital. Pun. I 288-290) y sabemos por su nombre antiguo -Saiganthé- que era de sobras conocida por ambas partes su riqueza debida al comercio marítimo y terrestre, así como su consideración-vinculada a este tema-como ciudad 
autónoma y libre (Liv. XXI 7, 2-3; App. Ib. 11; FL. I 22, 6). Pero lo más interesante es que ya en esa época el patrón monetal y los tipos de la ciudad ibera asociada (Arse) era idéntico al del dracma campano y que la existencia de divisores impide relacionar este hecho con los pagos de tropas (Aranegui Gascó 1994: 35-36. Knapp 1977: 206). Si añadimos a este hecho la existencia de una tradición clara de las monedas anteriores de esta ciudad a los referentes más inmediatos púnicos (Coleiro 1977: 99-102), la numismática misma puede demostrar el cambio de referente político de los saguntinos en estos años:

No obstante, es el propio avance de los hallazgos arqueológicos en los últimos años lo que nos permite aventurarnos en este camino. El volumen total de las ánforas halladas en este territorio saguntino demuestra la importancia de productos de la Magna Grecia y el sur de Italia desde época medio-republicana de manera similar a lo que ocurre en estas fechas en el Languedoc y Provenza franceses (Mantilla 1987-88: 379-416). Las mismas conclusiones pueden extraerse de los hallazgos de otras producciones específicamente itálicas como los vasos de Gnathia y los de Pequeñas Estampillas, que en opinión de Pérez Ballester "ilustran las relaciones entre las Penínsulas Ibérica e Itálica en un momento inmediatamente anterior a la Primera Guerra Púnica" (Pérez Ballester 1994: 193). E, incluso, en el Grau Vell se han encontrado restos de un torreón que posiblemente fuera un punto de vigilancia del sistema defensivo del antiguo puerto de Sagunto, que nos refiere la existencia de una importante planificación portuaria de la zona en época cartaginesa y una posible reconstrucción de la misma años más tarde por parte de los Escipiones. Todo ello, además, rodeado por un conjunto de materiales "protocampanienses" de barniz negro con cronología de la primera mitad del siglo III AC, así como de monedas del mismo arco cronológico posterior: 218-201 AC (AraneguiChiner-Hernández 1985: 201-216). Los propios datos que nos ofrece el comercio marítimo de esta zona y época nos permiten confirmar de principio estas indicaciones: la existencia de un interés material claro por parte de las poblaciones itálicas y siciliotas (entre las que se encuentra Roma como principal potencia política) en el litoral ibero desde principios del siglo III AC (Domínguez Pérez 1997-98: 107-113).

Todo este conjunto de datos modifica los hechos acontecidos en la misma dirección: la citada existencia de intereses económicos de Roma y de sus aliados en la Península Ibérica ya antes de la Primera Guerra Púnica y la entrada en competencia ya desde estos años con las posiciones comerciales cartaginesas que avanzaban hacia el norte hasta irrumpir con éxito en el entorno ampuritano (Cf. Tsirkin 1991: 147-152). Sin embargo, como hemos visto, la realidad a la que asisten los ciudadanos romanos, interesantemente manipulada por todos los resortes del poder, es meramente una elaboración ideológica de su dimensión económico-política. Es muy posible que los distintos colectivos con intereses manifiestos en la zona asociaran inmediatamente las dos caras de esta moneda, pero en ninguna valoración oficial aparecen estas preocupaciones materiales públicas ni privadas. En suma, lo que desde el poder se permite visualizar al ciudadano romano no es ni más ni menos que una coartada de corte religioso y moral que no manche las nobles orientaciones de la República con intereses "zafios".

Resulta evidente, pues, que la mentalidad oficial de la época en Roma aún está claramente sometida a los supuestos valores tradicionales del modelo republicano: moderación, austeridad, honor,...; pero más evidente resulta aún que esta mentalidad oficial ya no coincide con la que se manifiesta en las actuaciones reales (tanto del Estado como de sus ciudadanos) y que las distintas instituciones públicas y privadas (el Senado tanto como la familia y su clientela, por ejemplo) han adoptado la postura de negar "contra corriente" cualquier cambio. Dicho de otro modo, por más que el modo de producción está evidentemente sometido a un proceso de transformación definitivo, en cambio, su manifestación superestructural continúa siendo la misma que en el modo pasado. Se supone que el Estado -la clase gobernante-impone así un "freno de mano" a otros procesos de transformación no controlados. 


\section{EL PAPEL DEL ESTADO FRENTE A LA RIQUEZA Y LA ACUMULACIÓN MATERIAL}

Vistos estos indicios, cabría preguntarse cómo se manifiestan en los distintos niveles de la esfera ideológica estas transformaciones definitivas del modelo romano republicano, si existe o no existe desde el punto de vista institucional una contaminación de los motivos y de las respuestas oficiales.

Para no perder el control político uno de los aspectos en los que más se afana el Estado es la nueva tendencia al enriquecimiento. Las fuentes literarias nos indican que P. Licinio Craso, cónsul en $205 \mathrm{AC}$, fue el primero en recibir el cognomen "Dives" en referencia a una capacidad económica absolutamente fuera de lo común en aquellos tiempos (Liv. XXX 1, 4-6). Pero desde mucho antes era manifiesto el interés de los romanos por la acumulación material. Ya en el 311 AC el cónsul Junio Bubulco afirmaba no querer gloria, sino enriquecer a su tropa a costa del enemigo (Liv. X31, 10-11). En el 275 AC el senador S. Cornelio Rufino, dos veces cónsul y una dictador fue despojado de su condición en la cámara "quod decem pondo vasa argentea comparasset" y daba así ejemplo de amor al lujo (Dion. Hal. XX 13; Val. Max. II 9, 4). Y en 252, en plena Primera Guerra Púnica, se excluyó también a dieciséis senadores y se redujo a aerarii a cuatrocientos caballeros por desobediencia en Sicilia en asuntos relacionados con el botín y la rapiña (Liv. Per. XIX; Val. Max. II 9, 7).

Contra estos hechos la moral pública no tardaba en sancionar la política social del Estado. Tomemos ejemplos de la postura oficial ante estos hechos como el discurso de Fabricio en defensa de la sobriedad y austeridad como virtudes del ciudadano. Embajador del Senado ante Pirro en 279 AC, cuando es tentado por éste con regalos los rechaza argumentando que las únicas riquezas personales que aprecia son la dignidad, el prestigio y la popularidad conseguidas por medios honorables (Liv. Per. XIII; Dion. Hal. XIX 15-18; Dio IX fr. 40, 33-38; Zon. VIII 4, 4)

Otro ejemplo lo encontramos en Polibio, quien aún en la primera mitad del siglo II AC afirmaba que "los romanos alaban tanto la riqueza adquirida honradamente como rechazan el provecho extraido por medios inconfesables" (VI 56, 3). Otra historia sería concretar a qué llamaban los romanos "ganancias honorables". Ya en el citado discurso de Fabricio se aprecia claramente que el Estado, a través del común de sus instituciones, consideraba "honorables" todas las riquezas extraídas de una victoria y saqueo del territorio de los adversarios, siempre que se entregara al Tesoro público el total o la mayor parte de las riquezas conseguidas.

Un paso más en estas transformaciones que venimos analizando se recoge en la famosa laudatio funebris del cónsul Cecilio Metelo, fallecido dos años antes de que Aníbal sitiara Sagunto. Una vez más vinculado al mundo de los dioses, donde nada se cuestiona, aparece ya un cuadro de valores morales sensiblemente adaptado a los últimos cambios sociales. Ya se considera legítima la apropiación de parte del botín y de las tierras conquistadas por parte del general victorioso, aunque se sigue considerando la inversión agraria -en contra del comercio-como la única actividad económica digna. Con todo, se vuelve a utilizar una justificación moral que reconozca institucionalmente este enriquecimiento al referirse a "pecuniam magnam bono modo invenire" (Plin. NH VII 139-140; Gabba 1981: 543). A lo que no se refería el cónsul es cómo se podía hacer mucho dinero "bono modo" si no se sacaban a mercado los productos que el campo tan escrupulosamente había dado.

En este sentido cabe entender también el elogio del campesino-soldado como modelo ideal de ciudadano romano hasta mediados del siglo III AC que hace Catón (De agr., Praef.). En él no sólo justifica esta consideración social basándose en que la agricultura proporciona las ganancias más justas y en que no produce envidias ni malas intenciones, sino, sobre todo, al valorar el comercio como una actividad muy peligrosa y expuesta a la ruina, aceptable en fin, pero sólo como forma de vida mejor que la usura, verdadera lacra social en Roma.

Pero el Estado no se contenta con la vía moral y religiosa. Otro de los poderosos instrumentos con que cuenta para el control del cuerpo cívico es el aparato jurídico, verdadera garantía contra desarrollos sociales revolucionarios. Al sistema plagado de limitaciones, controles y condiciones se suma la periódica emisión de leyes cuya finalidad última sigue siendo el reforzamiento -posible o no- del cuerpo social. Así, por 
ejemplo, la Lex Claudia de nave senatorum del 218 AC prohibía tácitamente a los senadores y a sus hijos el ejercicio de actividades comerciales de ultramar, considerando indigno para éstos (que -recordemosejercían unilateralmente el poder político) cualquier clase de lucro (Liv. XXI 63, 3-4). Al margen de que el significado de la citada ley demuestra a las claras la existencia de senadores antes de la Segunda Guerra Púnica dedicados al comercio marítimo en masa (nada parecido al de autoconsumo que la propia ley y el sentido moral republicano recomendaban y autorizaban), resulta interesante saber que el Estado intenta frenar ese hecho de considerable valor emulatorio global presentando a los intereses una disyuntiva seca: o senadores con la dignitas pública dedicados a las labores políticas-con sus beneficios indirectos implícitoso comerciantes sin ella dedicados a la búsqueda de las riquezas y la acumulación material.

\section{BIBLIOGRAFÍA}

ARANEGUI GASCÓ, C. (1994): “Arse-Saguntum: una estrategia para consolidar el poder”, Leyenda y arqueología de las ciudades prerromanas de la península ibérica I: 31-43. Madrid.

ARANEGUI, C.; CHINER, P.; HERNÁNDEZ, E. et alii (1985): "El Grau Vell de Sagunt, Campaña de 1984", Saguntum 19: 201-216.

BALBI DE CARO, S. (1982): "Cause sociali ed economiche alla base della politica monetaria di Roma, IV e II secolo AC", Roma Repubblicana fra il 509 e il 270. Archeologia e Storia a Roma (DonderoPensabene): 107-113. Roma.

BROUGHTON, T.R.S. (1968): The Magistrates of the Roman Republic, vol. I. Cleveland-Ohio.

BUONO-CORE VARAS, R. (1988): "La mentalidad política y religiosa de Roma en el siglo III a.C.", MHA IX: 7-19.

COLEIRO, E. (1977): "The first challenge to Roman domination in Spain. Hannibal's excuse for attacking Saguntum", Helmantica XXVIII: 97-102.

D'ARMS, J. (1981): Commerce and Social Standing in Ancient Rome. Cambridge.

DE MARTINO, F. (1979): Storia economica di Roma Antica. Florencia.

DEVELIN, R. (1978): "Religion and Politics at Rome during the Third Century BC", JRH X: 3-19.

DOMÍNGUEZ PEREZ, J.C. (1995): La guerra y el imperialismo romano de época republicana. Introducción historiográfica. Cádiz (Memoria de Licenciatura inédita).

(1997-98): "Notas para una nueva interpretación del interés romano por nuestra península anterior al 218 AC a la luz de los últimos hallazgos de ánforas vinarias greco-itálicas", Mainake XIX-XX: 107-113.

GABBA, E. (1981): "Ricchezza e classe dirigente romana fra III e il I sec. AC", RSI XCIII III: 541-558

HARRIS, W.V. (1979): War and Imperialism in Republican Rome 327-70 BC. Oxford.

KNAPP, R.C. (1977): Aspects of the Roman experience in Iberia, 206-100 B.C. Valladolid-Vitoria.

MACBAIN, B.(1982): Prodigy and expiation: a study in religion and politics in Republican Rome. Bruselas. MANTILLA COLLANTES, A. (1987-88): “Marcas y ánforas romanas encontradas en Saguntum”, Saguntum 21: 379-416.

PAVOLINI, C. (1982): "Ruolo commerciale di Roma tra il V e il III secolo AC e produzione ceramica" Roma Repubblicana fra il 509 e il 270. Archeologia a Storia di Roma (Dondero-Pensabene): 101-105. Roma.

PÉREZ BALLESTER, J. (1994): "La cuestión de las importaciones itálicas al sur del Ebro anteriores a las Guerras Púnicas. A propósito de un vaso de Gnathia procedente de Ibiza”, Saguntum 27: 189-196. SCHEID, J. (1981): La religión en Roma: 99-118. Madrid.

SZEMLER, G.J. (1972) The Priests of the Roman Republic. A Study of Interactions between Priesthoods and Magistracies. Bruselas.

TSIRKIN, J.B. (1991): "El Tratado de Asdrúbal con Roma", POLIS 3: 147-152. 